\title{
Erratum to: Similar frequency of the McGurk effect in large samples of native Mandarin Chinese and American English speakers
}

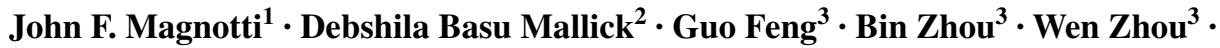 \\ Michael S. Beauchamp ${ }^{1}$
}

Published online: 25 March 2016

(C) Springer-Verlag Berlin Heidelberg 2016

\section{Erratum to: Exp Brain Res (2015) 233:2581-2586 \\ DOI 10.1007/s00221-015-4324-7}

This paper was inadvertently published in a regular issue of Experimental Brain Research in 2015, even though it was earmarked for the Special Issue on Multisensory Processing. The Special Issue appeared in Experimental Brain Research in the May 2016 issue (Vol. 234, Issue 5).

The online version of the original article can be found under doi:10.1007/s00221-015-4324-7.

John F. Magnotti

magnotti@bcm.edu

1 Department of Neurosurgery, Baylor College of Medicine, 1 Baylor Plaza, Suite 104, Houston, TX, USA

2 Department of Psychology, Rice University, Houston, TX, USA

3 Key Laboratory of Mental Health, Institute of Psychology, Chinese Academy of Sciences, Beijing 100101, China 